\title{
Relation of inflammation and liver function with the plasma cortisol response to adrenocorticotropin in early lactating dairy cows
}

\author{
E. Trevisi, ${ }^{1}$ G. Bertoni, R. Lombardelli, and A. Minuti \\ Istituto di Zootecnica, Facoltà di Agraria, Università Cattolica del Sacro Cuore, via Emilia Parmense 84, 29122 Piacenza, Italy
}

\begin{abstract}
In this study we examined the relationship between cortisol and inflammatory status in early lactating dairy cows after a stimulation test of the adrenal cortex. Twenty-four cows were grouped into quartiles (6 cows per each quartile) in accordance with the liver activity index (based on plasma concentration of negative acute phase proteins in early lactation); the quartiles were lower (LO; cows with the lowest liver functionality), intermediate lower, intermediate upper, and upper (UP; cows with the highest liver functionality). Each cow was injected i.v. with $20 \mu \mathrm{g}$ of a synthetic analog of ACTH at $35 \mathrm{~d}$ in milk (DIM). Blood samples were taken to assess inflammatory status, and at 0,30 , and $60 \mathrm{~min}$ after ACTH challenge to measure total cortisol. The free cortisol fraction was analyzed in the LO and UP quartiles and the bound cortisol fraction was estimated as the difference between total and free cortisol. The LO, in comparison with the other quartiles, suffered a more severe inflammatory status, with the highest values of haptoglobin, reactive oxygen metabolites, and total nitric oxide metabolites and the lowest concentration of direct or indirect markers of negative acute phase proteins. The cows in the LO quartile had the highest values of plasma nonesterified fatty acids and $\beta$-hydroxybutyrate at 7 DIM, suggesting a more severe body lipid mobilization. The LO quartile cows showed the highest frequency of health problems and the lowest milk yield in the first 35 DIM. Thirty minutes after the ACTH treatment, the concentration of total cortisol was lower in LO in comparison to other groups. Similarly, the bound cortisol fraction was lower in LO versus UP. The adrenal response appeared inversely related with health status after calving (e.g., lower in LO cows, experiencing the most severe inflammatory status). The lower increase in cortisol after the ACTH challenge in cows with greater inflammation (LO quartile) seems a consequence of the lower availability of cortisol-binding globulin synthetized by the liver, but
\end{abstract}

Received November 13, 2012.

Accepted May 19, 2013.

${ }^{1}$ Corresponding author: erminio.trevisi@unicatt.it other mechanisms can be involved (e.g., rate of cortisol production, secretion, and metabolic clearance). Our data provide evidence that inflammation and metabolic changes reduce the concentration of circulating plasma cortisol during an acute stress. Hence, the acute phase response in dairy cows should be taken into account to interpret the results obtained from stimulation tests of the adrenal cortex.

Key words: acute phase response, cortisol-binding globulin, adrenocorticotropin (ACTH) challenge, dairy cow

\section{INTRODUCTION}

Dairy cows suffer inflammation-like conditions during the periparturient period, often without any clinical symptom of disease (Bertoni et al., 2008). The main physiological effects of these conditions concern a change of the liver function due to the stimulation of the acute phase response and a reduction of some usually produced plasma proteins (Fleck, 1989; Bruss, 1997; Gruys et al., 2005; Bionaz et al., 2007). This circumstance is characterized by the quick induction of the synthesis of positive acute phase proteins (posAPP; e.g., haptoglobin, serum amyloid A) and the reduction of the negative acute phase protein (negAPP) synthesis (e.g., albumin, apolipoproteins, retinol binding protein, transferrin, transthyretin; Ceciliani et al., 2012).

It is noteworthy that the cortisol concentration can be affected by the availability of the circulating cortisol-binding globulin (CBG) produced in the liver, which is the main carrier of the hormone (Tyrrell and Forsham, 1986). Interestingly, the CBG concentration is known to be reduced in cases of inflammatory conditions (Pugeat et al., 1989; Christ-Crain et al., 2007) to such an extent that Gruys et al. (2005) considered CBG as a neg-APP. Therefore, inflammation might reduce the maximum concentration of bound plasma cortisol after ACTH challenge by reducing the level of CBG. As free cortisol has a very short half-life (about 2.2 min in healthy humans; Dorin et al., 2012), the reduction of the CBG affects the maximum concentration of total plasma cortisol. This consideration agrees 
with the conclusion of Christ-Crain et al. (2007), who suggested caution in the interpretation of the ACTH challenge results, in humans affected by diseases of different severity, if only based on total serum cortisol concentration.

In farm animals, the ACTH challenge is the main stimulation test used to demonstrate the sensitization of the adrenal cortex, and it is proposed to assess the welfare status (Broom, 1988; Mormède et al., 2007). The interpretation of this test remained uncertain and controversial, as reviewed by Mormède et al. (2007), who concluded "effects are not consistent across the studies that use similar treatments." In fact, several factors interfere with the adrenal responsiveness (e.g., age, environment, health status, social interaction), and a few of them can be clearly identified under the habitual conditions of life. Among that, we hypothesize that, in dairy cows, the CBG concentration is reduced during an acute-phase response (e.g., periparturient time when clinical and subclinical disorders are more frequent), and this decreases the total plasma cortisol response during a stimulation test of the adrenal cortex. To test this hypothesis we investigated the adrenal response (measured as the maximum plasma concentration of free and total cortisol) in early lactating cows grouped by different inflammatory conditions, evaluated with the liver activity index (LAI; which includes albumin, cholesterol, and vitamin A; Bertoni et al., 2008) and challenged with ACTH.

\section{MATERIALS AND METHODS}

\section{Animals and Housing}

This study complied with Italian laws on animal experimentation (DL n.116, 27/01/1992) and ethics. The experiment was carried out in a commercial dairy farm in northern Italy, during the autumn and winter seasons and involved 24 multiparous Italian Friesian lactating cows in their first 40 DIM. The cows had free access to water and feed. The diet was administered ad libitum once a day $(0800 \mathrm{~h})$ as a TMR. During the dry period, the diet included $33.6 \%$ corn silage, $21.4 \%$ alfalfa hay, $27.7 \%$ grass hay, $17.3 \%$ wheat straw (DM basis), and $100 \mathrm{~g} /$ cow per day of mineral-vitamin supplement. Ten days before calving, cows received a close-up ration composed of $42.3 \%$ corn-silage, $15.3 \%$ alfalfa hay, $11.2 \%$ grass hay, $6.3 \%$ wheat straw, and $24.9 \%$ concentrate (DM basis). After calving, the cows received a TMR composed of $32.1 \%$ corn-silage, $19.8 \%$ alfalfa hay, $4.4 \%$ grass hay, $10.5 \%$ high-moisture corn, and $33.1 \%$ concentrate, which included micro-mineral and vitamin supplements (DM basis). Cows were milked twice a day

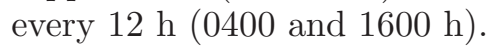

\section{Prechallenge Controls and Grouping}

For 4 wk after calving, each subject was monitored daily for health status and milk yield. The incidence of clinical diseases was recorded (retained placenta, milk fever, lameness, mastitis, ketosis, diarrhea). At $7 \pm 1$, $14 \pm 2$, and $35 \pm 2$ DIM, individual blood samples (Vacuum Li-Heparin, Vacuette, Kremsmünster, Austria) were taken from the jugular vein before feed distribution. These samples were used to assess the concentration of albumin, cholesterol (index of lipoprotein), and vitamin A (index of retinol binding protein) and to calculate LAI for each cow, according the procedures previously described by Bertoni et al. (2008), with the exception of the third blood sample taken at 35 DIM instead of 28 DIM. Briefly, data of the 3 blood parameters were transformed into units of standard deviation obtained for each cow by the mean value of the herd population of each plasma parameter subtracted from each cow value at 7,14 , and 35 DIM and divided by the corresponding standard deviation. The final LAI of each cow is the result of the arithmetical mean of the 3 partial values obtained from the 3 selected blood variables at the 3 bleedings. Changes in neg-APP and LAI values in periparturient cows are closely related with specific inflammatory markers [e.g., haptoglobin, syalic acid, reactive oxygen metabolites (ROM); Trevisi et al., 2010b], as well as to impaired performance (Bertoni et al., 2008). Thus, we used LAI to differentiate the inflammatory condition among cows during their first month of lactation. Cows with lower LAI values had worse inflammatory status than cows with higher LAI values. Accordingly, the 24 cows were grouped into quartiles based on their LAI: upper quartile (UP; n $=6$ ), cows with the highest values of LAI; intermediate upper quartile (INUP; $\mathrm{n}=6$ ); intermediate lower quartile (INLO; $\mathrm{n}=6)$; and lower quartile $(\mathbf{L O} ; \mathrm{n}=$ 6 ), cows with the lowest values of LAI.

\section{ACTH Challenge}

At the end of the first month of lactation $(35 \pm 2$ DIM), the 24 cows were challenged with ACTH. Cows were managed as usual on the day of the challenge. Approximately $3 \mathrm{~h}$ after the morning meal, cows were gently restrained in the headlock. The ACTH challenge protocol was reported previously (Trevisi et al., 2010a). Briefly, a dose of Synacthen $(20 \mu \mathrm{g}=2$ IU diluted in a total volume of $2 \mathrm{~mL}$ of physiological saline solution) was injected into the jugular vein. The Synacthen is a synthetic analog of ACTH (Novartis Pharma AG, Stein, Switzerland). The injected dose was defined in previous experiments (Bertoni et al., 2005) as the smallest amount of Synacthen able to reach the maxi- 
mum value of total cortisol in the blood. Blood samples for total and free cortisol measurements were taken immediately before the ACTH injection (time 0), and exactly 30 and 60 min postinjection. The farm workers, using care to avoid fright, captured the cows, and the blood sample was collected within 5 min from capture. Cows were restrained in the headlock during challenge and were observed for any kind of adverse reactions (e.g., agitation, anxiety, fear). The BCS was estimated according to a 5-point scale (ADAS, 1986) at the end of the ACTH challenge to better characterize the condition of the cows at 35 DIM.

\section{Blood Assays}

Immediately after collection, blood samples were cooled in an ice-water bath. A small amount of blood was used for package cell volume $(\mathrm{L} / \mathrm{L})$ determination (Centrifugette 4203, ALC International Srl, Cologno Monzese, Italy) and the remainder was centrifuged within $1 \mathrm{~h}$ from the collection at 3,500 $\times g$ for $15 \mathrm{~min}$ at $4^{\circ} \mathrm{C}$. The plasma obtained was frozen $\left(-20^{\circ} \mathrm{C}\right)$ in several aliquots until analysis.

All the plasma samples collected in the first month of lactation were analyzed at $37^{\circ} \mathrm{C}$ in a clinical autoanalyzer (ILAB 600, Instrumentation Laboratory, Lexington, MA). Glucose $(\mathrm{mmol} / \mathrm{L})$, total protein $(\mathrm{g} / \mathrm{L})$, albumin $(\mathrm{g} / \mathrm{L})$, total cholesterol $(\mathrm{mmol} / \mathrm{L})$, total bilirubin $(\mu \mathrm{mol} / \mathrm{L})$, triglycerides $(\mathrm{mmol} / \mathrm{L})$, creatinine (mmol/L), urea (mmol/L), Ca (mmol/L), P (mmol/L), $\mathrm{Mg}(\mathrm{mmol} / \mathrm{L})$, aspartate aminotransferase (U/L), $\gamma$-glutamyl transpeptidase (U/L), and alkaline phosphatase $(\mathrm{U} / \mathrm{L})$ were determined using kits purchased from Instrumentation Laboratory (IL Test). Globulin (g/L) was calculated as the difference between total protein and albumin. Electrolytes [Na, K, and $\mathrm{Cl}(\mathrm{mmol} / \mathrm{L})]$ were detected by a potentiometer method (Ion Selective Electrode connected to ILAB 600$)$. Zinc $(\mu \mathrm{mol} / \mathrm{L})$ and NEFA (mmol/L) were determined by commercial kits (Wako Chemicals GmbH, Neuss, Germany), as well as the total plasma ROM (mg of $\mathrm{H}_{2} \mathrm{O}_{2} / 100 \mathrm{~mL}$; Diacron International s.r.l., Grosseto, Italy). Haptoglobin $(\mathrm{g} / \mathrm{L})$, BHBA $(\mathrm{mmol} / \mathrm{L})$, and ceruloplasmin $(\mu \mathrm{mol} / \mathrm{L})$ were analyzed using methods previously described by Bertoni et al. (2008), adapting them to the ILAB 600 analyzer. Plasma nitric oxide metabolites (NOX) was measured using the Griess test according to Gilliam et al. (1993) and Bouchard et al. (1999). Plasma paraoxonase $(\mathbf{P O N})$ activity $(\mathrm{U} / \mathrm{mL})$ was measured by adapting the method of Ferré et al. (2002) to the ILAB 600, as described by Bionaz et al. (2007). Moreover, plasma vitamins $\mathrm{A}(\mu \mathrm{g} / 100 \mathrm{~mL}), \mathrm{E}(\mu \mathrm{g} / \mathrm{mL})$ and $\beta$-carotene $(\mathrm{mg} / 100 \mathrm{~mL})$ were extracted with hexane and analyzed by reverse-phase HPLC using the following operative conditions: Allsphere ODS-2.3 $\mu \mathrm{m}$, in a $150 \times 4.6 \mathrm{~mm}$ column (Alltech, Deerfield, IL); an UV detector set at $325 \mathrm{~nm}$ for vitamin A (retinol), $290 \mathrm{~nm}$ for vitamin E ( $\alpha$-tocopherol), and $460 \mathrm{~nm}$ for $\beta$-carotene; a solution of 80:20 methanol:tetrahydrofurane as mobile phase. The within-assay and between-assay CV were less than $3 \%$ for all blood parameters.

\section{Total and Free Cortisol Assay}

The plasma concentration of total cortisol was measured in all the samples collected during the ACTH challenge using a direct solid-phase radioimmunoassay (Coat-A-Count kit, Siemens Medical Solutions Diagnostics, Los Angeles, CA). The release of cortisol was achieved with the aid of blocking agents for steroidbinding proteins. The assay was adapted and validated for bovine plasma by modifying the standard curve range $(2.5-200 \mathrm{ng} / \mathrm{mL})$ and the sample volume $(50 \mu \mathrm{L}$ instead of $25 \mu \mathrm{L}$ ). The observed concentrations compared with the expected ones of cortisol were $99 \pm$ $9 \%$ when different dilutions of bovine samples were assayed to check for linearity. The within-assay CV were $3.1,5.4$, and $7.0 \%$ at plasma concentrations of 130,41 , and $6 \mathrm{ng} / \mathrm{mL}$, respectively; the corresponding betweenassay CV were $2.5,3.6$, and $9.5 \%$.

The concentration of free cortisol was determined in the plasma samples of LO and UP LAI quartiles collected at 0 and 30 min after the ACTH challenge. The free fraction of cortisol was obtained via a temperaturecontrolled UF of plasma (Lentjes et al., 1993) using the Microcon YM-30 centrifugal filter device (cut-off 30,000, Millipore \#42409, Millipore S.p.A., Vimodrone, Italy). The unbound cortisol in the ultrafiltrate was measured using the solid-phase RIA kit described above. The bound fraction was estimated from the difference between total and free cortisol.

\section{Statistical Evaluation}

The data measured over time (plasma components) within the period of interest were arranged in 2 data sets: morning samples $(7,14,35 \mathrm{DIM})$ and challenge samples $(0,30$, and 60 min after the ACTH injection). These data were subjected to ANOVA using the REPEATED statement in the MIXED procedure of SAS (SAS Institute Inc., Cary, NC; release 8.0). Tendencies were considered at $P<0.10$ and statistical significance was considered at $P<0.05$. The statistical model included the fixed effects of the group (UP, INUP, INLO, LO), DIM $(7,14,35)$, the time from the ACTH challenge $(0,30,60 \mathrm{~min})$, and the interaction of group by DIM or group by time (min). The random variable was cow within the group (UP, INUP, INLO and LO). Each 
Table 1. The main features and performances of cows used to the ACTH challenge (2 IU), grouped according to liver activity index (LAI) level in the lower (LO), lower intermediate (INLO), upper intermediate (INUP), and upper (UP) quartiles ${ }^{1}$

\begin{tabular}{|c|c|c|c|c|c|c|c|c|}
\hline \multirow[b]{2}{*}{ Item } & \multicolumn{4}{|c|}{ LAI quartile } & \multirow[b]{2}{*}{ SEM } & \multicolumn{3}{|c|}{$P$-value } \\
\hline & $\mathrm{LO}$ & INLO & INUP & UP & & Model & LAI & $\mathrm{LAI} \times \mathrm{DIM}$ \\
\hline Lactation (n) & 3.83 & 3.83 & 2.80 & 3.17 & 0.4213 & 0.266 & - & - \\
\hline BCS & 2.26 & 2.16 & 2.19 & 2.03 & 0.0999 & 0.457 & - & - \\
\hline \multicolumn{9}{|c|}{ Milk yield (kg/d) } \\
\hline
\end{tabular}

${ }^{1}$ The statistical evaluation was carried out comparing the INLO, INUP, and UP against the LO group.

$* P<0.05 ; * *<0.001$.

parameter was tested for normal distribution using the Shapiro test (SAS Inst. Inc.) and normalized by logarithmic transformation when necessary. The logarithmic transformation was applied to BHBA, aspartate aminotransferase, alkaline phosphatase, total bilirubin, and NOX, all other variables were normally distributed. Each variable was subjected to 3 covariance structures (autoregressive order, compound symmetry, and spatial power); as the autoregressive order resulted in the best fit, it was used as the covariance structure.

The Pearson correlations between blood parameters (at 7, 14, and 35 DIM) and total cortisol (basal and during the challenge) were calculated for all cows. In addition, the Pearson correlations between blood parameters (at 7, 14, and 35 DIM) and free and bound cortisol (0 and 30 min after the challenge) were calculated for cows of the LO and UP quartiles.

\section{RESULTS}

Descriptive statistics are given as mean \pm SEM. For convenience, all descriptive data are presented in their original form.

\section{LAl in Tested Cows}

The individual scores of the LAI calculated on the 24 tested cows ranged from -1.13 to 0.81 . The average levels of LAI differed significantly among the quartiles (Table 1). The 3 parameters included in this index (albumin, cholesterol, and vitamin A) progressively increased in the first month of lactation between the LO to the UP quartile. Consequently, the plasma concentrations of albumin $(P<0.01)$, vitamin $\mathrm{A}(P<$ 0.01 ), and cholesterol (NS) were lower for the whole first month of lactation in LO compared with the other 3 quartiles.

\section{LAI, Performance, and Health Status}

The groups did not show any difference concerning parity and BCS at 35 DIM (Table 1). Conversely, the
LO group had a lower milk yield at 14 DIM compared with the 3 remaining groups $(P<0.01)$. At 35 DIM, the milk yield in the LO group increased, but remained about $4 \mathrm{~kg} / \mathrm{d}$ lower than the other quartiles (NS). During the first month of lactation, some of the cows suffered clinical health problems, such as lameness, diarrhea, or ketosis. The highest incidence of illness was observed in the LO group ( $75 \%$ of subjects) in comparison to the other 3 groups $(50,33,17 \%$ of cows with at least 1 illness in INLO, INUP, and UP, respectively).

\section{LAI and Blood Profiles}

The patterns of change of pos-APP and some acute phase reactants are shown in Table 2. Both the measured pos-APP (haptoglobin and ceruloplasmin) had the highest concentrations immediately after calving (7-14 DIM) in all the quartiles. The LO and INLO groups had the highest postpartum concentrations of haptoglobin, and significant differences were reached between the LO compared with INUP and UP quartiles $(P<0.01$ and 0.05 , respectively) at 7 DIM. At 35 DIM, haptoglobin and ceruloplasmin were reduced in all the groups.

Both ROM, an important marker of oxidative stress, and NOX had the highest concentrations in the LO quartile and the lowest concentrations in UP, particularly at 7 DIM $(P<0.05$; Table 2$)$. The intermediate quartiles had intermediate values between the LO and UP groups, but INLO showed lower levels than INUP until 14 DIM.

Plasma vitamin E and PON (Table 2) had a comparable trend to the above 3 neg-APP included in the LAI. Vitamin E had the highest differences between the LO and the INUP quartiles. The plasma concentration of total bilirubin was highest in the LO quartile for the first 2 wk of lactation, in particular at 7 DIM $(P<0.05$ vs. INLO and $P<0.01$ vs. INUP and UP; Table 2). 
Table 2. Pattern of changes (average and SEM) of negative (paraoxonase) and positive acute phase proteins (haptoglobin and ceruloplasmin), and some related parameters in lower (LO), lower intermediate (INLO), upper intermediate (INUP), and upper (UP) quartiles of liver activity index $(\mathrm{LAI})^{1}$

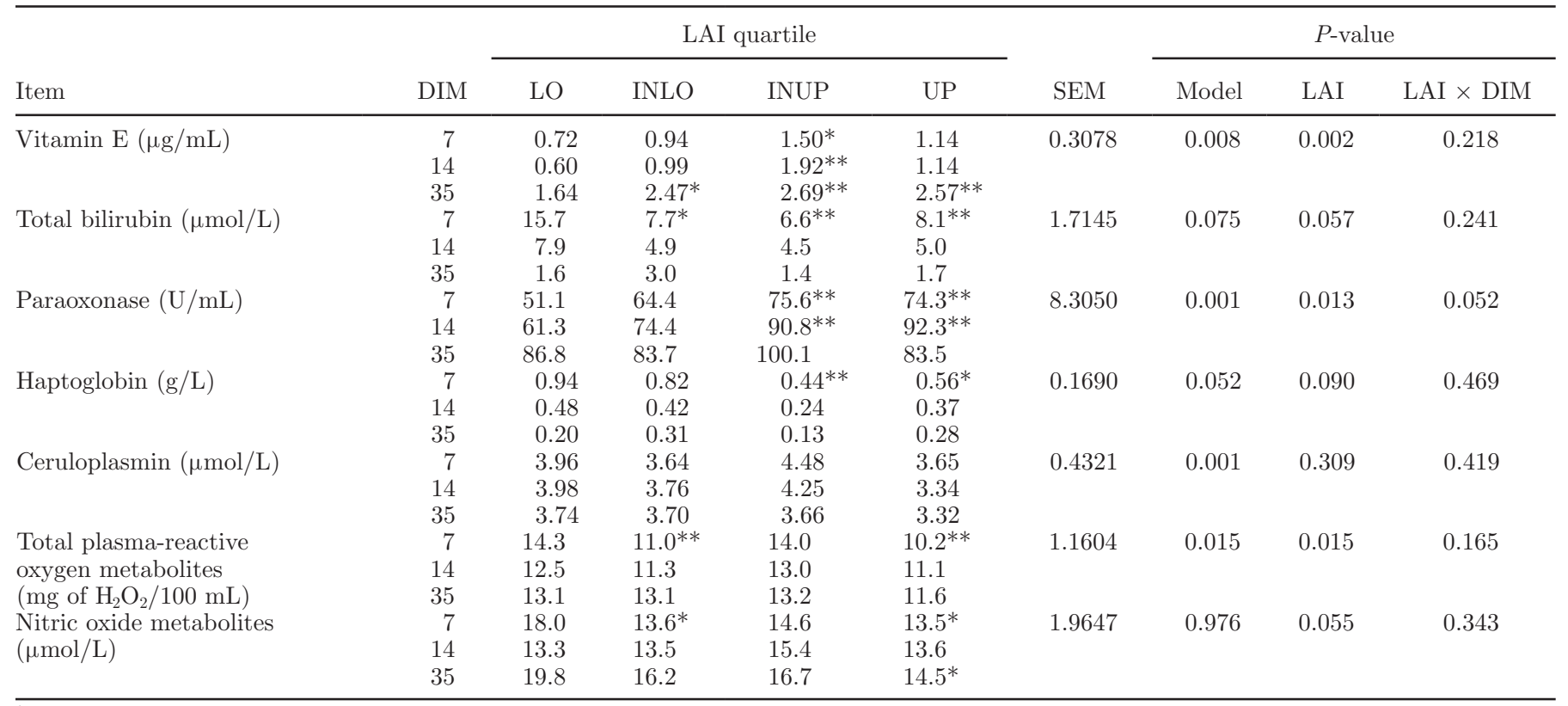

${ }^{1}$ The statistical evaluation was carried out comparing INLO, INUP, and UP against LO quartile.

${ }^{*} P<0.05$; ** $P<0.01$.

The LO quartile had the highest concentrations of plasma NEFA and BHBA in the first 2 wk after calving $(P<0.01$ vs. the other 3 quartiles at 7 DIM $)$. Plasma glucose was lower in LO for the entire period and statistical significance was reached at $7 \mathrm{DIM}(P<0.05$ vs. INLO and INUP, but not UP). Lastly, plasma urea had the lowest concentrations in the LO compared with the UP $(P<0.1$; Table 3$)$.

\section{LAI and ACTH Challenge}

During the ACTH challenge, cows remained calm and spent most of time eating and ruminating; thus, any adverse reaction was observed. The values of total cortisol measured before the ACTH challenge (Figure 1a) were not different $(P>0.05)$ between the quartiles and the average concentration was $6.91 \mathrm{ng} / \mathrm{mL}$. The adrenal response after the ACTH challenge caused a quick rise of plasma total cortisol (Figure 1a). At 30 min in the LO quartile, plasma total cortisol was lower than in the other quartiles $(P<0.05)$. One hour after the challenge, plasma total cortisol was reduced in comparison to the concentrations observed at $30 \mathrm{~min}$, and, despite the LO group maintaining the lowest values, the differences with the other quartiles were not significant.

The concentration of free cortisol (Figure 1b) was evaluated only in the cows from the 2 extreme groups of LAI (LO and UP). Free cortisol was very low before the ACTH challenge $(0.27 \mathrm{ng} / \mathrm{mL}$, about $5.1 \%$ of the total cortisol), and the concentrations were similar between LO and UP cows. Thirty minutes after ACTH challenge the free cortisol concentration increased versus the prechallenge time $(P<0.01)$, but the concentration did not differ between the 2 quartiles of LAI. At the same time (30 min after ACTH challenge), the bound plasma cortisol was lower in the $\mathrm{LO}(27.8 \mathrm{ng} / \mathrm{mL})$ compared with UP quartile $(37.6 \mathrm{ng} / \mathrm{mL} ; P<0.05)$.

\section{DISCUSSION}

The main objective of this study was to investigate whether the plasma cortisol rise occurring during a stimulation test of the adrenal cortex is affected by the level of systemic inflammation. In fact, inflammation reduces the levels of the neg-APP, a class of proteins including the CBG, the cortisol carrier (Gruys et al., 2005; Priftis et al., 2008). As previously suggested by Bertoni et al. (2008), the changes of neg-APP in the first month of lactation can be summarized by the LAI, which is based on the changes of albumin, lipoprotein (cholesterol), and retinol-binding protein (vitamin A). Thus, cows were assessed with the LAI and separated in classes according to the severity of inflammatory events at calving time. The LAI is based on the principle (Fleck, 1989) that the liver synthesis of pos-APP (e.g., C-reactive protein, haptoglobin, serum amyloid protein) hinders the production of the usually synthesized proteins (e.g., albumins, lipoproteins, retinol-binding 
Table 3. Pattern of changes (average and SEM) of plasma metabolic parameters in lower (LO), lower intermediate (INLO), upper intermediate (INUP), and upper (UP) quartiles of liver activity index (LAI) ${ }^{1}$

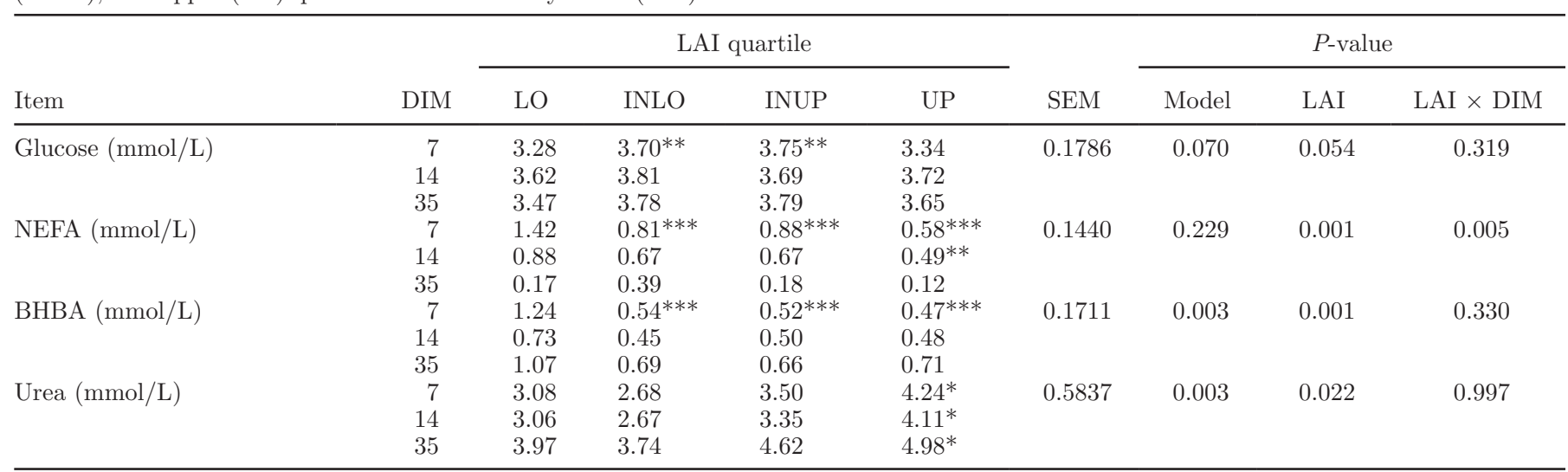

${ }^{1}$ The statistical evaluation was carried out comparing INLO, INUP, and UP against LO quartile.

${ }^{*} P<0.1 ;{ }^{* *} P<0.05 ;{ }^{* * *} P<0.01$.

protein). Our results basically confirm this assumption; LO cows showed higher values of haptoglobin, ROM, and NOX, all indices of inflammation.

\section{LAI and Other Indicators of Inflammation}

Other plasma parameters related to LAI exist. Indeed, LO cows had lower values of PON and vitamin E, as well as higher bilirubin. All these plasma indices are directly or indirectly (carriers) related to the changes in the liver protein syntheses (Tennant, 1997; Assenat et al., 2004). Some of these parameters were previously discussed in relation to the inflammatory conditions (Bionaz et al., 2007; Bertoni et al., 2008), but new and interesting connections appear from the results of the present experiment. The lower concentrations of PON during the first 2 wk of lactation in LO cows confirm that PON is also a neg-APP (Chait et al., 2005; Bionaz et al., 2007; Trevisi et al., 2012) and that LO cows suffered more severe consequences from the inflammatory status. Interestingly, PON was well correlated to negAPP in the first weeks of lactation (i.e., with vitamin $\mathrm{A} ; \mathrm{r}=0.7, P<0.01)$ and with cholesterol $(\mathrm{r}=0.65$, $P<0.01$ ). The more prolonged high values of plasma bilirubin after calving in $\mathrm{LO}$ versus the other quartiles was likely due to the impaired synthesis of the enzymes involved in its clearance during the inflammation, as suggested by Assenat et al. (2004).

The similar pattern of change for vitamin $\mathrm{E}$ and vitamin A suggests a reduction of their carriers at calving time and immediately after (Weiss et al., 1990; Smith et al., 1997; Bertoni et al., 2008). Vitamin E, unlike vitamin $\mathrm{A}$, is carried in the plasma by intestinal and hepatic lipoproteins, and no specific plasma transport proteins have been described (Bjørneboe et al., 1990; Kaempf-Rotzoll et al., 2003). Nevertheless, $\alpha$-tocopherol concentrations in plasma also depend on a hepatic intracellular trans- fer protein (tocopherol-binding protein) that regulates its shuttling in nascent, very-low-density lipoproteins (Burton, 1994). These circumstances explain the strong correlation of Vitamin E with cholesterol $(\mathrm{r}=0.7 ; P$ $<0.01$ ), a good index of lipoproteins that are mainly of liver origin in early lactation, and with vitamin A and PON $(\mathrm{r}=0.5$ and 0.6 , respectively; $P<0.05)$. Our data agree with the results of Rezamand et al. (2007), who observed a marked reduction of plasma vitamin $\mathrm{E}$ concentration in cows that experienced a new IMI immediately after calving.

Overall, in the first days of lactation, the link between the severity of inflammation and the pattern of changes of neg-APP was confirmed by the negative correlations calculated considering all cows; in particular, between haptoglobin and vitamin A at 7 DIM $(\mathrm{r}=-0.70, P$ $<0.01)$ and at 14 DIM $(\mathrm{r}=-0.54, P<0.01)$, as well as between haptoglobin and vitamin E at 7 DIM ( $\mathrm{r}=$ $-0.54, P<0.01)$. Further evidence for the connection between inflammation and neg-APP is the strong positive correlation between haptoglobin and total bilirubin at 7 DIM $(\mathrm{r}=0.71, P<0.01)$. In this context, the occurrence of the $75 \%$ of clinical problems in LO cows and only the $17 \%$ in UP cows cannot be considered a random event. This means a different frequency of diseases, which also cause inflammation. Nevertheless, our data confirm that inflammatory responses can occur without any clinical symptoms, as shown by $25 \%$ of LO cows (the share was near $50 \%$ in a previous experiment; Bertoni et al., 2008).

\section{LAl, Milk Yield, and Energy Balance in Tested Cows}

The LO cows showed the more severe inflammatory conditions and the higher incidence of health problems. Thus, if a lower milk yield of these cows is expected 

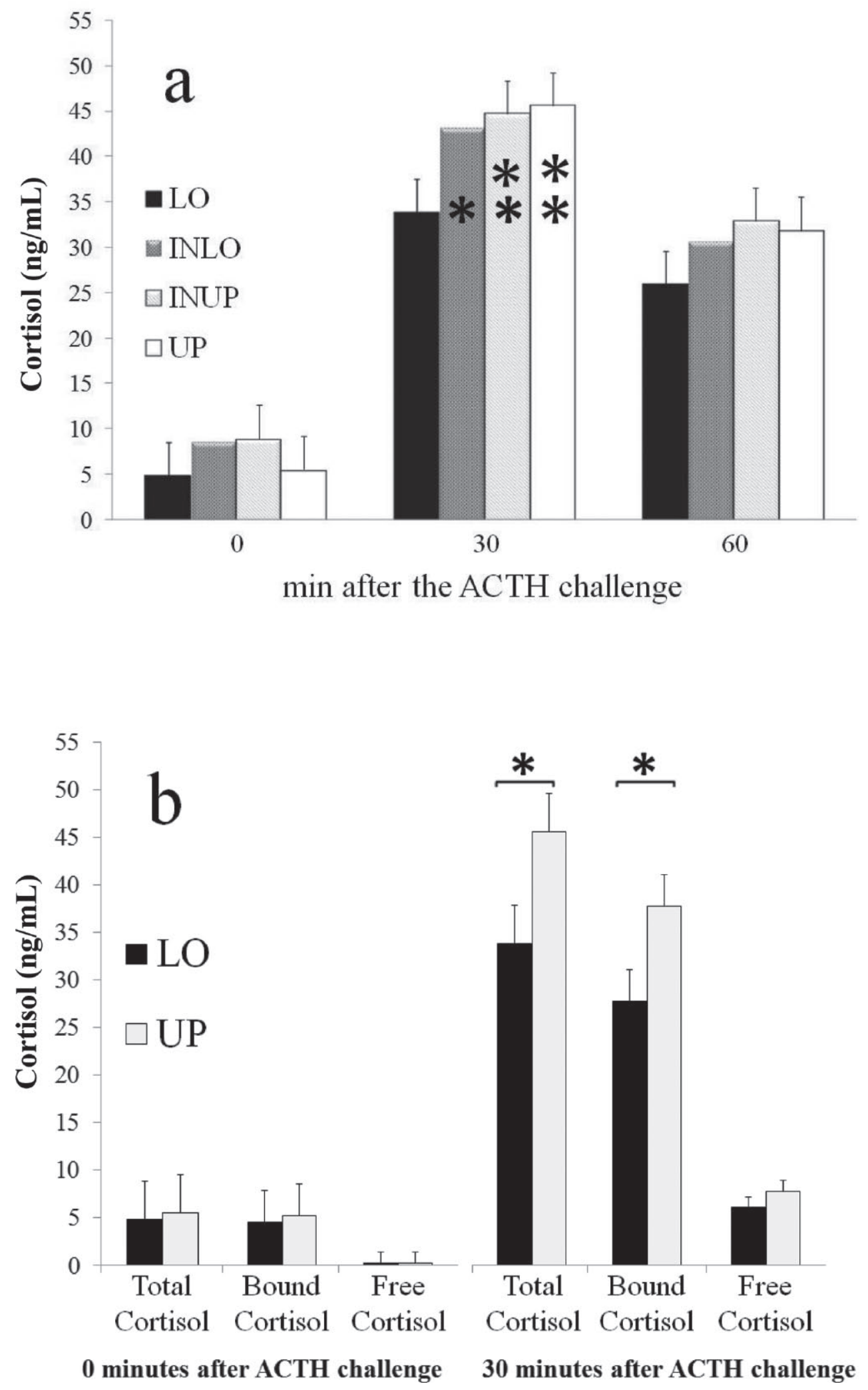

Figure 1. (a) Concentrations (average and SEM) of total plasma cortisol in the lower (LO), lower intermediate (INLO), upper intermediate (INUP), and upper (UP) quartiles of liver activity index (LAI) after the ACTH challenge (2 IU) carried out at 35 DIM. (b) Concentrations (average and SEM) of total, bound, and free cortisol in the UP and LO quartiles of LAI 30 min after the ACTH challenge. The statistical comparison between groups was carried out comparing the INLO, INUP, and UP against the LO group $\left(* P<0.05 ;{ }^{*} P<0.01\right)$. 
in respect to the other groups $(P<0.01$ at 14 DIM), the consequences on the body reserves use are more complex. During the first month of lactation, LO cows showed the highest blood concentrations of NEFA and BHBA along with the lowest concentration of glucose (Table 3). Moreover, plasma concentrations of NEFA and BHBA at 7 DIM were negatively correlated to the LAI $(\mathrm{r}=-0.70$ and -0.69 , respectively; $P<0.01)$. In a previous experiment (Trevisi et al., 2012), cows with severe inflammation in the first month of lactation had a lower DMI, a greater loss of BCS, a severe NEB, as well as higher concentrations of plasma NEFA and BHBA in comparison to cows with low inflammatory conditions. Though we did not measure feed intake in this trial and BCS was not different between groups at 35 DIM (but was not estimated at calving time), the higher NEFA and BHBA concentrations in the first month of lactation support the more marked and longer period of negative energy balance in LO cows, in accordance with the results of Drackley (1999) and Beever (2006).

\section{LAI and Plasma Cortisol}

The cows of LO quartile are characterized by the lowest levels of neg-APP, which was unchanged at 35 DIM, the time of the ACTH challenge (Table 2). In accordance with this, the reduced concentration of CBG (which is a neg-APP) can explain the significantly lower values of cortisol (total and bound) in LO group, consequent to the ACTH challenge. Interestingly, the concentrations of total cortisol at 30 min after ACTH challenge is positively correlated with LAI $(P<0.01$; Figure 2$)$, as well as with the concentrations of vitamin $\mathrm{E}$ at 14 and 35 DIM $(P<0.01)$ and PON at 14 DIM $(P<0.05)$ (Table 4). These correlations suggest an association between the severity of previous inflammatory processes [e.g., liver function (reduction of neg-APP) and the lower cortisol response after the ACTH challenge (LO cows)]. As previously suggested, the possible link could be the concentration of CBG, an $\alpha$-globulin also called transcortin, in blood. In humans, approximately $80 \%$ of total cortisol is bound to CBG, $10 \%$ to albumin, and $10 \%$ is the free fraction (le Roux, 2003; Vincent et al., 2009). A change of CBG would, accordingly, increase or reduce the bound cortisol, and consequently the total fraction. Thus, the reduction of CBG synthesis in the liver appears reasonable in our experiment. Nevertheless, additional mechanisms should be implicated in the reduction of the free and total plasma concentration (e.g., affinity of CBG with cortisol; rate of cortisol production, secretion and metabolic clearance), but these factors were not investigated in our study.
The relation of CBG with inflammation has been shown in humans; Pugeat et al. (1989) and le Roux (2003) signaled a drastic fall in CBG in patients with an acute-phase response (septic shock). Therefore, the lower total cortisol concentration observed after the ACTH challenge in cows with more severe inflammatory status (LO group), can be explained by a lower availability of its transporter (e.g., CBG) as a consequence of the lower hepatic synthesis of the usually produced proteins (called neg-APP). This is also supported by the reduction of the CBG gene expression in the liver of cows challenged with an intramammary LPS infusion (Jiang et al. 2008). Similar results were obtained by Carroll et al. (2003) after LPS treatment in piglets. In our study, the direct evaluation of CBG was not possible; therefore, we indirectly estimated its concentration by calculating bound cortisol as the difference between total and free cortisol. The bound fraction of cortisol was lower in LO in comparison to the UP quartile 30 min after ACTH challenge $(P<$ $0.05)$. The percentage of bound cortisol was similar in the 2 groups ( 83.2 and $82.5 \%$ ), and this seems to confirm the link with the same type of carrier. Thus, our results suggest a low concentration of CBG in the case of severe inflammation, which is maintained for a long time after the event. The positive correlations between bound cortisol 30 min after ACTH challenge and other direct or indirect markers of neg-APP (PON and vitamin $\mathrm{E}$ ) in the first month of lactation also contributed to support the linkage between inflammation and CBG level. Therefore, if inflammation is able to reduce the level of $\mathrm{CBG}$, the assessment of the adrenal gland response subsequent to the ACTH challenge could be misleading because the concentration of the total plasma cortisol can be lower independent of the adrenal gland response.

Overall, these results underscore the difficulty in the interpretation of the ACTH test results in many species (Bright and Darmaun, 1995; Dhillo et al., 2002; Poomthavorn et al., 2009; Trevisi and Bertoni, 2010). This supports the conclusion of Vincent et al. (2009), who stated "total cortisol measurement may underestimate cortisol production when CBG levels are low."

As a consequence, the reduced response to the ACTH challenge observed in LO cows is partly independent from the adrenal gland activity. From our results it is not possible to estimate this effect, but the results suggest caution in the use of the ACTH challenge test to assess stress. The ACTH challenge is a stimulation test used to demonstrate the sensitization of the adrenal cortex (Mormede et al., 2007), but the response of plasma cortisol in case of chronic stress is debatable. Broom (1988) reported the hyper-reactivity of the ad- 
Table 4. Correlations among liver activity index (LAI) and some blood parameters at different DIM with total and bound plasma cortisol $30 \mathrm{~min}$ after ACTH challenge

\begin{tabular}{lccc}
\hline Item & DIM & $\begin{array}{c}\text { Total cortisol } \\
(\mathrm{n}=24)\end{array}$ & $\begin{array}{c}\text { Bound cortisol } \\
(\mathrm{n}=12)\end{array}$ \\
\hline LAI & - & $0.56^{* *}$ & $0.60^{*}$ \\
Vitamin E & 14 & $0.52^{* *}$ & $0.79^{* *}$ \\
& 35 & $0.70^{* *}$ & $0.83^{* *}$ \\
Paraoxonase & 14 & $0.42^{*}$ & 0.47 \\
Total bilirubin & 35 & 0.02 & $-0.62^{*}$ \\
\hline
\end{tabular}

$* P<0.05 ; * * P<0.01$.

renal cortex (e.g., higher concentration of total cortisol) after the ACTH challenge in case of a chronic stress condition (e.g., high-stocking density, confinement, regrouping of unfamiliar animals), whereas Weiss et al. (2004) observed the contrary. Our experiment showed the lowest values of plasma cortisol (total and bound) after the ACTH challenge in LO cows, which appear to be the most chronically stressed according to several blood indices. Conversely, UP cows were in better condition (best health status as well as highest milk yield) and displayed the highest adrenal response (e.g., the higher concentrations of total plasma cortisol). Thus, our results are consistent with the conclusions of Weiss et al. (2004) and, in addition, support the hypothesis that the maximum concentration of total plasma cortisol is not only induced by the adrenal release of cortisol but also depends markedly on the CBG availability in the plasma.

\section{CONCLUSIONS}

Cows suffering severe inflammation are characterized by more pronounced consequences to the acute phase response (higher pos-APP and lower neg-APP). Among neg-APP, CBG synthesis could be reduced, resulting in a lower increase of circulating cortisol after acute stress of the adrenal gland. Therefore, the response of the adrenal gland during the ACTH challenge test could

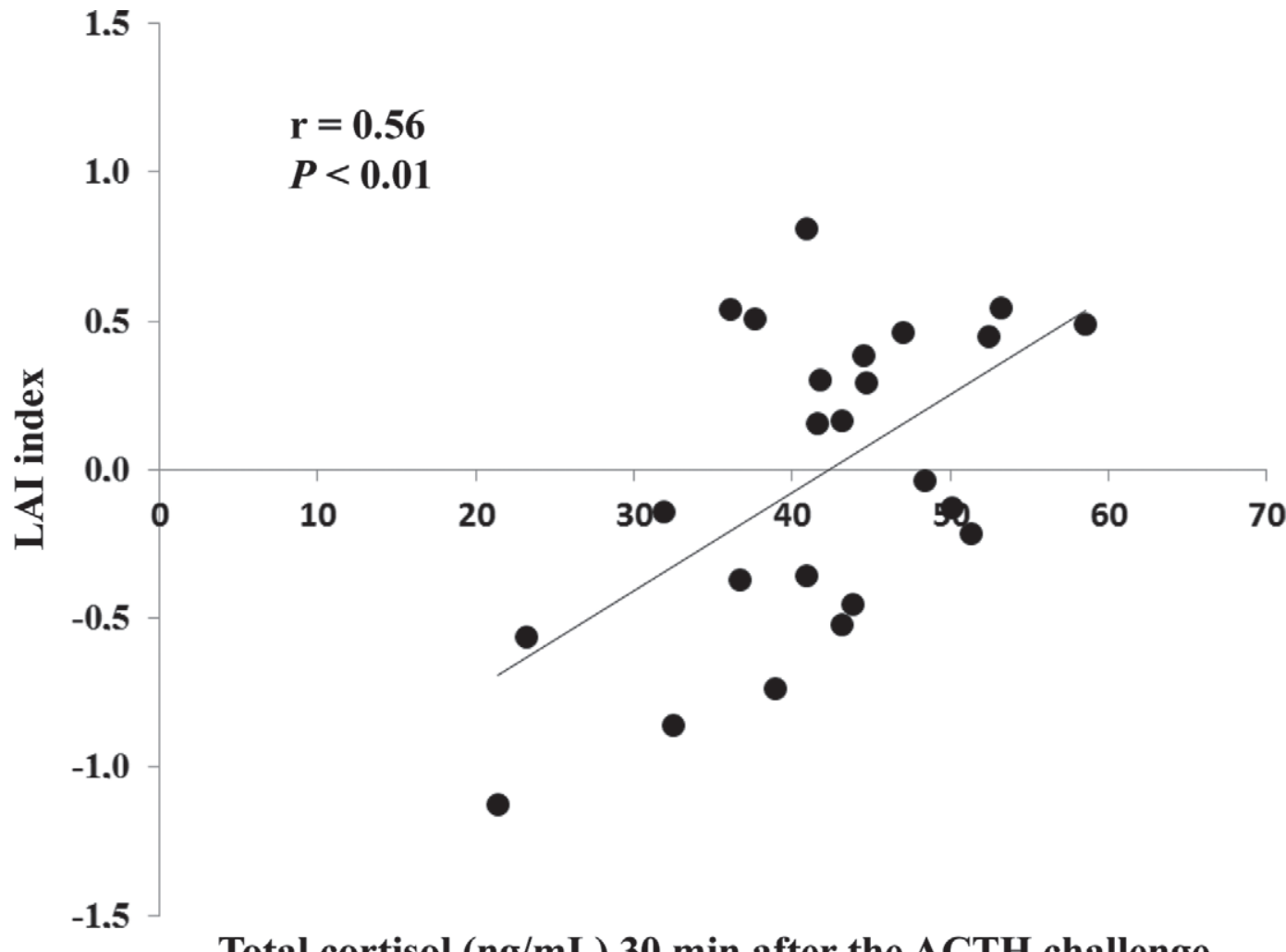

Figure 2. Correlation between the cortisol concentration 30 min after the ACTH challenge and the liver activity index (LAI) in the 24 dairy cows used in the trial. 
be appropriate, but the concentration of circulating cortisol in the plasma drops because the inadequate availability of its carrier. The CBG was not the only factor influencing the concentration of plasma cortisol, but tests to measure adrenal response have to take into account the influence of inflammation. Future research should include measures of the cortisol carrier (concentration and affinity with the cortisol), in addition to the hormone itself, to investigate the presence of alternative mechanisms.

\section{ACKNOWLEDGMENTS}

The authors thank Elena Gandolfi and workers of the Società Agricola Gandolfi Fausto \& C. (Carpaneto Piacentino, PC, Italy), who supported the conduct of the farm work.

\section{REFERENCES}

ADAS (Agricultural Development and Advisory Service). 1986. Condition Scoring of Dairy Cows. Publ. 612, Agric. Dev. Advisory Serv., Min. Agric., Fisheries Food, Lion House, Alnwick, Northumberland, UK.

Assenat, E., S. Gerbal-Chaloin, D. Larrey, J. Saric, J.-M. Fabre, P. Maurel, M.-J. Vilarem, and J. M. Pascussi. 2004. Interleukin 1beta inhibits CAR-induced expression of hepatic genes involved in drug and bilirubin clearance. Hepatology 40:951-960.

Beever, D. E. 2006. The impact of controlled nutrition during the dry period on dairy cow health, fertility and performance. Anim. Reprod. Sci. 96:212-226.

Bertoni, G., E. Trevisi, X. Han, and M. Bionaz. 2008. Effects of inflammatory conditions on liver activity in puerperium period and consequences for performance in dairy cows. J. Dairy Sci. 91:3300-3310.

Bertoni, G., E. Trevisi, R. Lombardelli, and L. Calamari. 2005. The ACTH challenge test to evaluate the individual welfare condition. In Book of Abstracts of the 56th Annual Meeting of the European Association for Animal Production. Wageningen Academic Publishers, Wageningen, the Netherlands.

Bionaz, M., E. Trevisi, L. Calamari, F. Librandi, A. Ferrari, and G. Bertoni. 2007. Plasma paraoxonase, health, inflammatory conditions, and liver function in transition dairy cows. J. Dairy Sci. 90:1740-1750.

Bjørneboe, A., G. E. Bjørneboe, and C. A. Drevon. 1990. Absorption, transport and distribution of vitamin E. J. Nutr. 120:233-242.

Bouchard, L., S. Blais, C. Desrosiers, X. Zhao, and P. Lacasse. 1999. Nitric oxide production during endotoxin-induced mastitis in the cow. J. Dairy Sci. 82:2574-2581.

Bright, G. M., and D. Darmaun. 1995. Corticosteroid-binding globulin modulates cortisol concentration responses to a given production rate. J. Clin. Endocrinol. Metab. 80:764-769.

Broom, D. M. 1988. The scientific assessment of animal welfare. Appl. Anim. Behav. Sci. 20:5-19.

Bruss, M. L. 1997. Lipids and ketones. Pages 83-115 in Clinical Biochemistry of Domestic Animals. 5th ed. J. J. Kaneko, J. W. Harvey, and M. L. Bruss, ed. Academic Press, San Diego, CA.

Burton, G.W. 1994. Vitamin E: Molecular and biological function. Proc. Nutr. Soc. 53:251-262.

Carroll, J. A., A. Gaines, J. Spencer, G. Allee, H. Kattesh, M. Roberts, and M. Zannelli. 2003. Effect of menhaden fish oil supplementation and lipopolysaccharide exposure on nursery pigs. Domest. Anim. Endocrinol. 24:341-351.

Ceciliani, F., J. J. Ceron, P. D. Eckersall, and H. Sauerwein. 2012. Acute phase proteins in ruminants. J. Proteomics 75:4207-4231.
Chait, A., C. Y. Han, J. F. Oram, and J. W. Heinecke. 2005. Lipoprotein-associated inflammatory proteins: Markers or mediators of cardiovascular disease? J. Lipid Res. 46:389-403.

Christ-Crain, M., S. Jutla, I. Widmer, O. Couppis, C. König, H. Pargger, J. Puder, R. Edwards, B. Müller, and A. B. Grossman. 2007. Measurement of serum free cortisol shows discordant responsivity to stress and dynamic evaluation. J. Clin. Endocrinol. Metab. 92:1729-1735.

Dhillo, W. S., W. M. Kong, C. W. Le Roux, J. Alaghband-Zadeh, J. Jones, G. Carter, N. Mendoza, K. Meeran, and D. O'Shea. 2002. Cortisol-binding globulin is important in the interpretation of dynamic tests of the hypothalamic-pituitary-adrenal axis. Eur. J. Endocrinol. 146:231-235.

Dorin, R. I., Z. Qiao, C. R. Qualls, and F. K. Urban. 2012. Estimation of maximal cortisol secretion rate in healthy humans. J. Clin. Endocrinol. Metab. 97:1285-1293.

Drackley, J. K. 1999. Biology of dairy cows during the transition period: The final frontier? J. Dairy Sci. 82:2259-2273.

Ferré, N., J. Camps, E. Prats, E. Vilella, A. Paul, L. Figuera, and J. Joven. 2002. Serum paraoxonase activity: A new additional test for the improved evaluation of chronic liver damage. Clin. Chem. $48: 261-268$.

Fleck, A. 1989. Clinical and nutritional aspects of changes in acutephase proteins during inflammation. Proc. Nutr. Soc. 48:347-354.

Gilliam, M. B., M. P. Sherman, J. M. Griscavage, and L. J. Ignarro. 1993. A spectrophotometric assay for nitrate using NADPH oxidation by Aspergillus nitrate reductase. Anal. Biochem. 212:359365.

Gruys, E., M. J. M. Toussaint, T. A. Niewold, and S. J. Koopmans. 2005. Acute phase reaction and acute phase proteins. J. Zhejiang Univ. Sci. B 6:1045-1056.

Jiang, L., P. Sørensen, C. Røntved, L. Vels, and K. L. Ingvartsen. 2008. Gene expression profiling of liver from dairy cows treated intra-mammary with lipopolysaccharide. BMC Genomics 9:443.

Kaempf-Rotzoll, D. E., M. G. Traber, and H. Arai. 2003. Vitamin E and transfer proteins. Curr. Opin. Lipidol. 14:249-254.

le Roux, C. W. 2003. Free cortisol index is better than serum total cortisol in determining hypothalamic-pituitary-adrenal status in patients undergoing surgery. J. Clin. Endocrinol. Metab. 88:2045-2048.

Lentjes, E.G., F. Romijn, R.J. Maassen, L. de Graaf, P. Gautier, and A. J. Moolenaar. 1993. Free cortisol in serum assayed by temperature-controlled ultrafiltration before fluorescence polarization immunoassay. Clin. Chem. 39:2518-2521.

Mormède, P., S. Andanson, B. Aupérin, B. Beerda, D. Guémené, J. Malmkvist, X. Manteca, G. Manteuffel, P. Prunet, C. G. van Reenen, S. Richard, and I. Veissier. 2007. Exploration of the hypothalamic-pituitary-adrenal function as a tool to evaluate animal welfare. Physiol. Behav. 92:317-339.

Poomthavorn, P., R. Lertbunrian, A. Preutthipan, A. Sriphrapradang, P. Khlairit, and P. Mahachoklertwattana. 2009. Serum free cortisol index, free cortisol, and total cortisol in critically ill children. Intensive Care Med. 35:1281-1285.

Priftis, K. N., A. Papadimitriou, P. Nicolaidou, and G. P. Chrousos. 2008. The hypothalamic-pituitary-adrenal axis in asthmatic children. Trends Endocrinol. Metab. 19:32-38.

Pugeat, M., A. Bonneton, D. Perrot, B. Rocle-Nicolas, H. Lejeune, C. Grenot, H. Déchaud, C. Brébant, J. Motin, and C. Y. Cuilleron. 1989. Decreased immunoreactivity and binding activity of corticosteroid-binding globulin in serum in septic shock. Clin. Chem. 35:1675-1679.

Rezamand, P., T. A. Hoagland, K. M. Moyes, L. K. Silbart, and S. M. Andrew. 2007. Energy status, lipid-soluble vitamins, and acute phase proteins in periparturient Holstein and Jersey dairy cows with or without subclinical mastitis. J. Dairy Sci. 90:5097-5107.

Smith, K. L., J. S. Hogan, and W. P. Weiss. 1997. Dietary vitamin $\mathrm{E}$ and selenium affect mastitis and milk quality. J. Anim. Sci. $75: 1659-1665$.

Tennant, B. C. 1997. Hepatic function. Pages 327-352 in Clinical Biochemistry of Domestic Animals. 5th ed. J. J. Kaneko, J. W. Harvey, and M. L. Bruss, ed. Academic Press, San Diego, CA. 
Trevisi, E., M. Amadori, S. Cogrossi, E. Razzuoli, and G. Bertoni. 2012. Metabolic stress and inflammatory response in high-yielding, periparturient dairy cows. Res. Vet. Sci. 93:695-704.

Trevisi, E., and G. Bertoni. 2010. Some physiological and biochemical methods for acute and chronic stress evaluation in dairy cows. Ital. J. Anim. Sci. 8:265-286.

Trevisi, E., R. Lombardelli, A. Minuti, and G. Bertoni. 2010a. Change of digesta passage rate in dairy cows after different acute stress situations. Ital. J. Anim. Sci. 6:377-379.

Trevisi, E., A. Zecconi, G. Bertoni, and R. Piccinini. 2010b. Blood and milk immune and inflammatory profiles in periparturient dairy cows showing a different liver activity index. J. Dairy Res. 77:310-317.

Tyrrell, B., and P. Forsham. 1986. Glucocorticoids and adrenal androgens. Pages 272-309 in Basic and Clinical Endocrinology. 2nd ed.
F. S. Greenspan and P. H. Forsham, ed. Lange Medical Publication, Los Altos, CA

Vincent, R. P., F. E. Etogo-Asse, T. Dew, W. Bernal, J. AlaghbandZadeh, and C. W. le Roux. 2009. Serum total cortisol and free cortisol index give different information regarding the hypothalamuspituitary-adrenal axis reserve in patients with liver impairment. Ann. Clin. Biochem. 46:505-507.

Weiss, D., S. Helmreich, E. Möstl, A. Dzidic, and R. M. Bruckmaier. 2004. Coping capacity of dairy cows during the change from conventional to automatic milking. J. Anim. Sci. 82:563-570.

Weiss, W. P., J. S. Hogan, K. L. Smith, and K. H. Hoblet. 1990. Relationships among selenium, vitamin $\mathrm{E}$, and mammary gland health in commercial dairy herds. J. Dairy Sci. 73:381-390. 